\title{
TEKNIK PENERJEMAHAN LISAN DALAM TRADISI BEKAYAT DI LOMBOK
}

\section{(INTERPRETING TECHNIQUE APPLIED ON ORAL TRADITION BEKAYAT IN LOMBOK)}

\author{
Safoan Abdul Hamid \\ Kantor Bahasa Provinsi NTB \\ Jalan dr. Sujono, Kelurahan Jempong Baru, Sekarbela, Mataram, NTB, Indonesia \\ Pos-el: safoan.hamid@gmail.com
}

Diterima: 27 Oktober 2014; Direvisi: 20 November 2014; Disetujui: 3 Desember 2014

\begin{abstract}
Sasak ethnic group's community in Lombok, Nusa Tenggara Barat Province, has an oral tradition of reciting hikayat namely bekayat. During the performance, step of the recitation is followed by interpretation from Melayu language to Sasak. As a part of literary work interpreting, the interpreter applies certain method, technique and ideology. This research is aimed at revealing interpreting technique applied in bekayat performance. Sample of this research is taken from Lombok Barat District, out of three other districts in Lombok. Data collection is conducted through recording and an interview technique. The data are transcribed and then analized by an interlinguistic and descriptive method. Result of the analysis shows that the interpreter of bekayat performance applied three techniques, namely paraphrase, contextual conditioning, and compensation.
\end{abstract}

Keywords: technique, interpreting, bekayat, Lombok

\begin{abstract}
Abstrak
Masyarakat suku Sasak di Pulau Lombok memiliki tradisi lisan pembacaan hikayat yang dikenal dengan bekayat. Dalam pelaksanaannya, tahap pembacaan hikayat dilanjutkan dengan penerjemahan lisan dari bahasa Melayu ke bahasa Sasak. Proses penerjemahan ini tergolong sebagai penerjemahan karya sastra yang memerlukan metode, teknik, dan ideologi tertentu. Penelitian ini bertujuan untuk mengurai teknik penerjemahan lisan dalam pelaksanaan tradisi bekayat. Adapun pengambilan sampel penelitian dilakukan disalah satu kabupaten di Lombok yakni Kabupaten Lombok Barat. Pengumpulan data dilakukan dengan teknik perekaman, wawancara, dan pencatatan. Selanjutnya data hasil perekaman pembacaan hikayat ditranskripsi dan dianalisis menggunakan metode intralingual dan metode deskriptif. Hasil analisis menunjukkan bahwa penerjemah lisan dalam proses bekayat menggunakan tiga teknik yakni teknik parafrasa, teknik penjelasan tambahan (contextual conditioning), dan teknik kompensasi.
\end{abstract}

Kata kunci: teknik, penerjemahan lisan, bekayat, Lombok

\section{Pendahuluan}

Masyarakat suku Sasak di Pulau Lombok, Provinsi Nusa Tenggara Barat, memiliki tradisi lisan pembacaan hikayat yang disebut bekayat atau nyaer. Tradisi ini diwariskan secara turun-temurun dalam masyarakat suku Sasak dan tergolong sebagai salah satu tradisi lisan bernafas Islam. Keberadaan tradisi ini tidak dapat dilepaskan dari masuknya agama Islam ke Indonesia yang juga membawa sastra yang berasal dari Timur Tengah. Saat itu sastra 
tulis di Indonesia mulai berkembang yang ditandai dengan ditulisnya hikayat-hikayat dengan huruf Arab-Melayu yang berisi kisah para Nabi, kisah kepahlawanan Islam, ajaran dan kepercayaan Islam, cerita fiktif, dan cerita mistik (tasawuf) (lihat Djamaris, 1993:109). Hikayat menjadi salah satu instrumen penting penyebaran ajaran agama Islam dalam wujud tradisi pembacaan hikayat. Kini tradisi bekayat menjadi penting karena berfungsi menjadi salah satu media pencerahan nilai-nilai dan konsep ajaran Islam di tengah era globlisasi yang cenderung menjauhkan masyarakat dari nilai-nilai agama.

Tradisi lisan bekayat memiliki ciri khas terkait estetika dan tujuan pertunjukannya. Suatu kelompok bekayat terdiri atas dua sampai enam orang personil masing-masing adalah pembaca naskah, penerjemah lisan atau juru bahasa (atau juga dikenal dengan pelogat atau bujangga), dan penyaruf yang berperan menyambut bacaan kalimat terakhir pembaca naskah sehingga pembacaan hikayat memiliki nuansa tertentu. Pembacaan hikayat menggunakan tembang-tembang tertentu seperti pangkur dan kumambang, termasuk juga dangdang dan sinom. Pemakaian tembang ini menjadi petunjuk adanya pengaruh budaya Jawa dan Bali dalam tradisi pembacaan hikayat di Lombok. Bekayat dilakukan pada acaraacara tertentu dan dengan kitab tertentu pula. Pada acara Maulid Nabi biasanya dibaca hikayat tentang sejarah kehidupan Nabi Muhammad Saw; pada acara Isra' Mi'raj dibaca hikayat Nur Muhammad; pada acara selamatan kematian dibaca kitab kasyful ghaibiah; pada acara akikah dibaca hikayat Nabi bercukur; pada acara perkawinan dibaca hikayat Nabi Yusuf. Namun terkadang jenis hikayat yang dibaca sesuai permintaan pihak yang empunya acara.

Dengan melihat jenis kitab yang dibaca, tradisi lisan bekayat bertujuan untuk kepentingan transmisi nilai-nilai agama
Islam agar dapat diimplementasikan dalam kehidupan sehari-hari. Oleh karena itu, sasaran pembacaan hikayat harus betul-betul mengerti dan mampu menghayati pesan yang disampaikan dalam teks bekayat. Dalam prosesi bekayat ada tahapan alih bahasa atau penerjemahan dari teks sumber (TSu) hikayat berbahasa Melayu ke bahasa sehari-hari yang digunakan oleh masyarakat setempat atau bahasa sasaran (BSa) pembacaan hikayat yakni bahasa Sasak. Alih bahasa dilakukan secara lisan sehingga proses menerjemahkan juga disebut penjurubahasaan dan penerjemahnya disebut juru bahasa.

Dalam proses alih bahasa itu, seorang penerjemah biasanya menggunakan metode, teknik, dan ideologi penerjemahan tertentu yang yang mungkin berbeda dari penerjemah lain. Untuk metode penerjemahan, ada penerjemah yang menggunakan metode penerjemahan bebas, harfiah, semantik atau komunikatif. Sedangkan terkait dengan teknik menerjemahkan, seorang penerjemah terkadang menggunakan teknik yang kaku dan ada juga yang menerapkan teknik yang cenderung luwes. Dengan teknik yang agak luwes seorang penerjemah bebas berkreasi dalam menerjemahkan, baik menambahkan atau mengurangi berbagai informasi yang secara langsung tidak terkait dengan teks hikayat. Adapun penerjemah yang menggunakan teknik yang cenderung literal tidak banyak menambahkan informasi yang tidak terkait dengan isi hikayat.

Belum ada penelitian yang fokus mengkaji metode, teknik, dan ideologi yang digunakan dalam proses penerjemahan tradisi lisan bekayat. Beberapa kajian yang telah dilakukan terkait tradisi lisan bekayat masih bersifat umum. Saharudin (2012) membahas fenomena stagnansi perkembangan tradisi lisan bekayat. Selain itu, Suyasa (2014) mengkaji tentang Reartikulasi Sastra Melayu dalam Tradisi 
Lisan Sasak, khususnya bekayat di Lombok. Penelitian ini bertujuan untuk mengungkapkan teknik penerjemahan lisan yang digunakan oleh penerjemah sastra lisan bekayat di Pulau Lombok. Penelitian ini penting untuk dilakukan karena memiliki manfaat teoritis dan praktis. Diharapkan kajian ini akan memberikan kontribusi terhadap pengembangan teori penerjemahan tradisi lisan Sasak secara khusus dan teori penerjemahan sastra secara umum. Adapun manfaat praktisnya adalah diharapkan kajian ini dapat memberikan wawasan dan menggugah kesadaran kita untuk mengapresiasi tradisi lisan bekayat sebagai bagian dari khazanah kekayaan budaya Nusantara.

\section{Kerangka Teori}

\subsection{Hikayat sebagai Sastra Indonesia Pengaruh Islam}

Hikayat berasal dari bahasa Arab hikayah yang berarti kisah, cerita, atau dongeng. Pengertian ini berasal dari tradisi sastra Arab dan Melayu lama (www.melayuonline.com). Dalam Kamus Besar Bahasa Indonesia (2013), hikayat didefinisikan sebagai karya sastra lama Melayu berbentuk prosa yang berisi cerita, undang-undang, dan silsilah bersifat rekaan, keagamaan, historis, biografis, atau gabungan sifat-sifat itu, dibaca untuk pelipur lara, pembangkit semangat juang, atau sekadar untuk meramaikan pesta, misalnya Hang Tuah, Perang Palembang, Seribu Satu Malam. Sedangkan berhikayat adalah bercerita, yang maksudnya adalah bercerita tentang isi kandungan hikayat. Berdasarkan isinya, hikayat digolongkan menjadi tiga jenis yakni rekaan, sejarah, dan biografi (www.melayuonline.com).

Hikayat merupakan jenis sastra Indonesia pengaruh Islam, yakni karya sastra yang ditulis setelah masuknya agama Islam ke Indonesia. Sebelumnya sastra Indonesia didominasi oleh sastra Hindu.
Beberapa contoh sastra lama pengaruh Islam itu ialah Hikayat "Nur Muhammad", "Hikayat Seribu Masalah", "Hikayat Nabi Mikraj”, "Kissasul Anbiya", dan lain-lain. (Djamaris, 1993:109, 111). Dengan kata lain, karya sastra yang ditulis sebelum masuknya agama Islam adalah sastra Indonesia pengaruh Hindu.

Melalui tradisi pembacaan hikayat, sastra tulis - hikayat - ditransformasi menjadi bentuk sastra lisan karena antara sastra tulisan dan lisan tidak ada perbedaan yang tegas. Dalam sastra Melayu, hikayat dan syair dibacakan secara keras kepada pendengar. Di Jawa ada tradisi pembacaan tembang macapat karya pujangga-pujangga besar yang didengarkan bersama-sama pada peristiwa-peristiwa adat penting. Di Bali, sampai sekarang, masih ada tradisi pembacaan babad atau kakawin yang dikenal dengan tradisi mabasan atau makakawin dalam bahasa Jawa Kuno yang kemudian diterjemahkan ke bahasa Bali (lihat Baried, 1994:59). Di Lombok juga terdapat tradisi pembacaan teks naskah lontar yang berasal dari Jawa yang dikenal dengan pepaosan - dalam tradisi ini kental adanya perpaduan tradisi Islam dan Hindu. Perpaduan itu dibuktikan dengan diadopsinya tembang-tembang yang berasal dari tradisi Hindu-Jawa karena Pulau Lombok pernah menjadi bagian dari koloni Kerajaan Hindu Karangasem.

\subsection{Konsep Penerjemahan Karya Sastra dan Jenis-Jenis Penerjemahan}

Untuk menuju karya kosmopolitan, sebuah karya sastra harus melalui pintu yang bernama penerjemahan. Karya sastra mendokumentasi budaya dan cara pandang masyarakat atau negeri tempat lahirnya. Dengan diterjemahkannya karya sastra, masyarakat dari berbagai negeri dengan latar belakang bahasa dan budaya yang berbedabeda ikut menjadi penikmat dan pecintanya. Karya sastra besar dunia juga banyak 
terlahir dari proses penerjemahan, contohnya penerjemahan atau penyaduran karya sastra yang berasal dari India ke bahasa Jawa kuno seperti Kakawin Ramayana, Mahabarata, Arjuna Wiwaha, Kakawin Hariwangsa, dan lain-lain, termasuk diantaranya adalah penerjemahan karya sastra yang berasal dari Arab dan Persia seperti Hikayat Anbiya, Hikayat Zakariya, Hikayat Hur Muhammad, Hikayat nabi Bercukur, Hikayat Sama'un Hikayat Sultan Ibrahim ibn Adham (Baried, 1994:87--88).

Definisi penerjemahan menurut Newmark (1988:5) adalah "rendering the meaning of a text into another language in the way that the author intended the text." Penerjemahan adalah pengalihan makna suatu teks ke bahasa lain untuk menghasilkan teks seperti yang dimaksudkan oleh penulis. Newmark memandang penerjemahan sebagai suatu proses pengalihan makna. Teks dalam BSa harus memiliki makna atau pesan yang sedekat mungkin dengan makna atau pesan dalam bahasa sasaran (BSa) sehingga pembaca dapat menangkap maksud sebenarnya dari penulis teks sumber (TSu).

Penerjemahan karya sastra menurut Robinson (dalam Suryawinata, dkk.: 2003) merupakan usaha untuk menjembatani dua kultur yang berbeda, dengan dua bahasa yang berbeda. Lebih-lebih ketika karya sastra yang diterjemahkan tergolong teks lama, faktor budaya menjadi permasalahan penting. Asumsinya, dalam teks lama, antara teks sumber (Tsu) dan TSa terjadi "jarak waktu" (temporal distance) dan "jarak budaya" (cultural distance) yang jaraknya harus diperkecil oleh seorang penerjemah (Hoed, 2006: 32-33).

Selain, itu seorang penerjemah karya sastra juga harus memiliki kemampuan terkait gaya bahasa. Kridalaksana (dalam Nababan, 2008: 19) mengungkapkan pentingnya gaya bahasa dalam terjemahan yakni penerjemahan merupakan pemindahan suatu amanat dari bahasa sumber ke dalam bahasa sasaran dengan pertama-tama mengungkapkan maknanya dan kemudian gaya bahasanya. Selain dituntut memiliki penguasaan bahasa dan budaya, seorang penerjemah karya sastra juga dituntut untuk memiliki kemampuan interpretasi teks yang kuat.

Venuti (dalam Hoed, 2006) mendefinisikan penerjemahan "Translation is a process by which the chain of constitutes source-language text is replaced by a chain of signifier in the target language which the translator provides on the strength of an interpretation."

"Penerjemahan merupakan suatu proses dimana rangkaian teks bahasa sumber digantikan dengan dengan rangkaian penanda dalam bahasa sasaran dan seorang penerjemah mengandalkan kekuatan interpretasi."

Definisi yang dikemukakan oleh Venuti di atas menonjolkan pentingnya interpretasi dalam menerjemahkan teks, khususnya teks sastra lama.

Secara umum, terdapat beberapa jenis penerjemahan, yakni penerjemahan tulis dan penerjemahan lisan. Dalam konteks penerjemahan karya sastra, penerjemahan tulis dibagi menjadi dua yakni penerjemahan prosa dan puisi. Adapun penerjemahan lisan dibagi menjadi empat jenis, yaitu a) tulislisan (sight translation), b) penerjemahan konsekutif (consecutive interpretation), c) penerjemahan simultan (simultaneous interpretation), d) dan penerjemahan secara berbisik (whispered interpretation) (Keiser dan Weber, dalam Nababan: 2008). Pembacaan hikayat atau bekayat masuk kategori penerjemahan konsekutif. Dalam penerjemahan konsekutif, seorang penerjemah mengucapkan hasil terjemahan setiap kali pembicara mengucapkan beberapa kalimat dan umumnya dilakukan ke satu arah (Tim Penyusun Modul Diklat Penerjemahan, 2013:6). Begitu juga halnya 
dalam proses bekayat, penerjemah mulai menerjemahkan setiap kalimat yang dibaca oleh pembaca teks hikayat.

\subsection{Metode dan Teknik Penerjemahan}

Kualitas hasil terjemahan ditentukan oleh metode dan teknik penerjemahan yang digunakan oleh seorang penerjemah, baik lisan maupun tulisan.

\subsubsection{Metode Penerjemahan}

Menurut Newmark

(1988:45), permasalahan mendasar dalam penerjemahan adalah apakah seorang penerjemah menerjemahkan secara harfiah atau bebas. Selanjutnya Newmark mengemukakan delapan metode penerjemahan yakni (1). penerjemahan kata demi kata (word-for-word-translation), (2) penerjemahan harfiah (literal translation), (3) penerjemahan setia (faithful translation), (4) penerjemahan semantis (semantic translation), (5) saduran (adaptation), (6) penerjemahan bebas (free translation), (7) penerjemahan idiomatis (idiomatic translation), dan (8) penerjemahan komunikatif (communicative translation). Terkait dengan metode, menurut Hoed (2006:9), cara menerjemahkan tidak hanya satu jenis, bergantung pada untuk siapa dan apa tujuan suatu penerjemahan. Oleh karena itu sebelum menerjemahkan perlu dilakukan desain sasaran dan analisis kebutuhan. Dalam penerjemahan tradisi lisan bekayat, penggunaan metode harus mempertimbangkan siapa sasaran dan penikmat bekayat, bagaimana latar belakang sosial, budaya, dan tingkat pendidikannya.

\subsubsection{Teknik Penerjemahan}

Teknik penerjemahan digunakan untuk tataran yang lebih rendah daripada teks, yakni kalimat atau unit bahasa yang lebih kecil. Ada beberapa contoh teknik penerjemahan (Newmark dan Mason; dalam Tim Penyusun Modul Diklat Penerjemahan,
2013:32--36). Pertama transposisi yaitu penerjemahan dengan mengubah struktur kalimat. Kedua, modulasi yaitu pengubahan sudut pandang untuk menghasilkan terjemahan yang berterima. Ketiga, penerjemahan deskriptif yaitu penerjemahan dengan pendeskripsian. Keempat, penerjemahan fonologis yaitu mempertahankan kata atau ungkapan yang digunakan dalam TSu dan TSa dengan menyesuaikan ejaannya dengan kaidah BSa. Kelima, parafrasa yaitu mengatakan makna pesan yang sama denga cara lain. Keenam, penjelasan tambahan (contextual conditioning) yaitu memberikan padanan dan kata tambahan dalam TSa. Ketujuh, kompensasi yaitu penghilangan suatu unsur TSu dan mengomensasinya dengan konteks. Kedelapan, catatan kaki yaitu menambahkan catatan kaki untuk menjelaskan konteks. Kesembilan, padanan budaya (adaptasi) yaitu pengungkapan konsep yang dialihkan dengan unsur budaya lokal. Kesepuluh, penerjemahan resmi/diakui yaitu menerjemahkan suatu teks yang begitu penting sehingga perlu diresmikan atau mendapat pengakuan resmi. Kesebelas, transferesi yaitu pemungutan kata dari TSu ke TSa. Keduabelas, calque yaitu menerjemahkan dengan memungut juga dari TSu namun sambil menciptakan kata baru dalam BSa.

\section{Metode Penelitian}

Tulisan ini disusun berdasarkan studi lapangan yang dilakukan di Desa Taman Ayu Kecamatan Gerung, Kabupaten Lombok Barat, Provinsi Nusa Tenggara Barat. Data penelitian ini diperoleh dengan metode wawancara dengan teknik cakap, catat, dan rekam. Peneliti merekam aktifitas pembacaan bekayat yang dilakukan oleh satu kelompok bekayat yang terdiri atas tiga orang personil yang masing-masing berperan sebagai pembaca hikayat, penerjemah, dan penyarup. Adapun data 
sekunder didapatkan melalui proses wawancara dan pencatatan mengenai berbagai aspek terkait pembacaan hikayat yang dilakukan dengan personil bekayat, masyarakat sekitar, dan perangkat desa setempat.

Data primer yang terkumpul berupa rekaman kegiatan pembacaan hikayat yang selanjutnya ditranskripsi ke bentuk tulisan. Hasil transkripsi terdiri atas teks sumber (TSu) berbahasa Melayu dan teks sasaran (TSa) berbahasa daerah Sasak. Hasil transkripsi selanjutnya dianalisis menggunakan metode komparatif intralingual dan metode deskrptif. Dengan metode komparatif intralingual, TSu dibandingkan dengan TSa dengan tujuan untuk menemukan teknik penerjemahan yang digunakan oleh penerjemah lisan (juru bahasa). Langkah-langkah yang dilakukan adalah a) mengamati teks asli berbahasa Arab Melayu yang dibaca oleh salah seorang informan; b) mengamati hasil transkripsi terjemahan untuk melihat kesepadanan semantis dan gramatikal antara teks TSu berbahasa Arab Melayu dan TSa berbahasa Sasak; c) membuat kategori penerjemahan/ penjurubahasaan yang digunakan oleh Sang juru bahasa. Sementara itu, metode deskriptif digunakan untuk menjelaskan prosedur penerjemahan/ penjurubahasaan yang digunakan dalam kegiatan bekayat di Desa Taman Ayu.

\section{Pembahasan}

Dengan menggunakan metode analisis data di atas, teknik penerjemahan lisan yang digunakan dalam tradisi bekayat Sasak di Lombok Barat adalah sebagai berikut.

\subsection{Teknik Parafrasa}

Parafrasa adalah pengungkapan kembali suatu tuturan dari sebuah tingkatan atau macam bahasa menjadi yang lain tanpa mengubah pengertian (Kamus Besar Bahasa Indonesia; 2013). Dalam penerjemahan, baik lisan maupun tulisan, teknik parafrasa sering digunakan untuk dapat menghasilkan terjemahan yang mudah dipahami dan tidak membuat penikmat bosan karena sifat terjemahan yang terlalu literal. Ketika menerapkan teknik ini, seorang penerjemah mengungkapkan atau menguraikan kembali teks atau tuturan BSuke dalam BSa tanpa merubah makna dan isi pesan BSu. Berikut ini adalah teks terjemahan lisan dari BSu (bahasa Melayu) ke BSa (bahasa Sasak) yang diterjemahkan menggunakan teknik parafrasa:

(1) BSu: Maka dihisabkan lidahnya dan masuklah atasnya empat orang malaikat.

BSa: Penyerioq temateq pemirsâ, pendengahtetemateq, biwihte maraq basâ kasar saq gen muni temateq juluq, ye boq ne tame malaikat becerite eleq sidâ tiang si gen mate.

$$
\begin{aligned}
& \text { Bahasa Indonesia: Penglihatan } \\
& \text { dimatikan pemirsa, } \\
& \text { pendengaran dimatikan, bahasa } \\
& \text { kasarnya mulut kita yang akan } \\
& \text { berbicara dimatikan juga, } \\
& \text { kemudian masuk malaikat } \\
& \text { bercerita kepada kita yang akan } \\
& \text { meninggal dunia. }
\end{aligned}
$$

Dalam menerjemahkan teks bekayat ini, penerjemah mengungkapkan kembali isi pesan $\mathrm{BSu}$ dengan menggunakan pilihan kata sendiri dan dengan perluasan kosakata secara horizontal dalam BSa. Satu kata dalam BSu diuraikan menjadi satu frasa panjang dalam BSa. Kata "lidahnya" diparafrasa dalam BSa menjadi biwihte maraq basâ kasar saq gen muni, maksudnya "bahasa kasarnya, mulut kita yang akan berbicara'. Penguraian menjadi frasa atau kalimat membantu dalam menyeimbangkan irama. Selanjutnya, "masuklah atasnya empat orang malaikat" diparafrasa ke dalam BSa menjadi ye boq neq tame malaikat becerite eleq sidâ tiang si gen mate, 
maksudnya "kemudian masuk malaikat bercerita kepada kita yang akan meninggal dunia”. Dalam penerjemahan di atas, frasa diparafrasa menjadi satu frasa yang lebih panjang. Dalam BSa ada penambahan dan pengurangan kosakata "empat orang malaikat" menjadi "malaikat", sedangkan kata "malaikat" diberi penjelasan tambahan "becerite eleq sidâ tiang si gen mate": bercerita kepada kita yang akan meninggal dunia".

Ada dua bentuk teknik prafrasa yang digunakan oleh penerjemah untuk menerjemahkan kutipan transkripsi kalimat bekayat di atas yaitu, i) kata diparafrasa menjadi frasa; ii) frasa diparafrasa menjadi frasa.

(2) BSu: He Hamba Allah, akulah malaikat yang diwakilkan dengan minuman engkau daripada air.

BSa: Taoqdâ ke tiang niki Bapaq? tiang niki si bagiang sidâ aiq si kadundâ nginem lengan dâ masih kodeq lengan aiq susun memendâ laeq niki, pokokn berupa aiq tiang doang siq wah bagiang sidâ.

Bahasa Indonesia: tahukah engkau siapa saya ini Bapak? Sayalah yang membagikan Bapak air yang Bapak minum sejak masih kecil dari air susu ibumu dulu, pokoknya berupa air, saya lah yang bagikan engkau

Dalam penerjemahan di atas, frasa yang pendek diparafrasa atau diungkapkan menjadi satu frasa yang lebih panjang dan frasa diparafrasa menjadi kata. Frasa "He hamba Allah" diparafrasa menjadi Taoqdâ ke tiang niki Bapaq: "tahukah engkau siapa saya ini Bapak”. Dalam proses prafrasa, penerjemah menambahkan frasa Taoqdâ ke tiang niki Bapaq: "tahukah engkau siapa saya ini Bapak”, yang berfungsi sebagai penegasan. Adapun frasa hamba Allah diganti menjadi Bapaq, yang sama-sama berfungsi sebagai kata sapaan. Selanjutnya, frasa "akulah malaikat" diparafrasa menjadi "tiang niki". Kata "malaikat" dihilangkan dalam BSa. Frasa "minuman engkau daripada air" diparafrasa menjadi kalimat "aiq si kadundâ nginem lengan dâ masih kodeq lengan aiq susun memendâ laeq niki, pokokn berupa aiq tiang doang siq wah bagiang sidâ: air yang Bapak minum sejak masih kecil dari air susu ibumu dulu, pokoknya berupa air, saya lah yang bagikan engkau". Tambahan kalimat pada BSa itu berfungsi sebagai penjelasan kata "air" dalam BSu.

Teknik parafrasa yang digunakan oleh penerjemah dalam menerjemahkan teks bekayat itu terdiri atas dua jenis. Pertama, frasa dalam $\mathrm{BSu}$ diparafrasa menjadi frasa dalam BSa, dengan penambahan dan pengurangan kosakata. Kedua, frasa diparafrasa menjadi kalimat yang berfungsi sebagai penjelas.

(3) BSu: Maka direntangkan akan dia atasnya berkata, "tilik olehmu kepada amal engkau."

BSa : Ke kusetelang sidâ felm de tuaq de boyaq, ndaq dâ ngéngatngéngat lain, maraq beleq layar tancep kedekuq tivi niki terang gambar ne suerenâ jelas, tulisanâ jelas tesetelang siq malaikat si lengan kawan.

Bahasa Indonesia: Aku putar rekaman film engkau Paman, silahkan dilihat dan jangan memandang yang lain. Seperti tv yang besarnya seperti layar tancap, suaranya terang, gambarnya jelas, dan terang tulisannya itu diputar oleh malaikat yang berada pada sebelah kanan.

Dalam proses penerjemahan di atas, kalimat diparafrasa menjadi kalimat. Dalam penerjemahan di atas kalimat "tilik olehmu" diparafrasa menjadi ndaq dâ ngengat- 
ngengat lain: "jangan memandang yang lain". Kalimat perintah dalam BSu berubah menjadi kalimat larangan dalam BSa. Selanjutnya, frasa "amal engkau" diparafrasa menjadi kalimat "maraq beleq layar tancep kedekuq tivi niki terang gambar nâ suerenâ jelas, tulisanâ jelas tesetelang siq malaikat si lengan kawan:" seperti tv yang besarnya seperti layar tancap, suaranya terang, gambarnya jelas, dan terang tulisannya itu diputar oleh malaikat yang berada pada sebelah kanan." Kata "tv" adalah majas metafora untuk menjelaskan catatan amal (rekaman amal) manusia kelak di akhirat karena semua amal manusia akan diperlihatkan dengan jelas.

(4) BSu: Kemudian meniliklah ia akan ke kanan dan ke kiri.

BSa: Na sesuai dait setelante jari manusia siq idup niki kelampan te maraq sandiwarâ, araq jaq manusiâ lueq pegaweanâ si kenaq niki, laguq lueq pegawean ne siq salaq, pacunâ ibadah laguq pacu nâ gaweq salaq, araq jaq dengan ndeq naraq gati pegaweanâ siq kenaq, ketungkulane gaweq pegawean salaq, araq jaq dengan ndeq naraq siq kenaq ndeq naraq siq salaq, macâmmacâm keq kaset idupte le bawon dunia niki.

Bahasa Indonesia: Nah, sesuai rekaman kehidupan kita sebagai manusia, perjalanan hidup kita seperti sandiwara, ada manusia yang banyak melakukan perbuatan baik namun banyak juga perbuatan salahnya. Dia banyak beribadah tapi banyak juga melakukan perbuatan salah. Ada orang yang tidak pernah melakukan kebaikan, terlena melakukan perbuatan salah. Ada orang yang tidak perbuatan baiknya dan tidak ada pula perbuatan buruknya. Beragam rekaman hidup kita di muka bumi ini.

Dalam penerjemahan di atas, kalimat pendek diparafrasa menjadi kalimat panjang sebagai hasil interpretasi. Dalam proses parafrasa penerjemah menginterpretasi kata "kanan" sebagai pegaweanâ si kenaq: "amal baik" dan kata "kiri" sebagai pegawean salaq: "amal buruk." Umumnya kanan identik dengan hal-hal baik sedangkan kiri identik dengan hal-hal buruk. Selain itu, dalam proses parafrasa tersebut, kata meniliklah: "memandang" dalam BSa dihilangkan.

(5) BSu : Kemudian berpalinglah malaikat itu

BSa: Assalamualaikum ... serempak malaikatsiq keduâ niki salam....pamiiit siq bilin sidâ tiang siq rapet ajal.

bahasa Indonesia: Assalamualaikum, serempak malaikat yang kedua ini mengucapkan salam... pamit meninggalkan kita yang ajalnya sudah dekat

Penerjemahan di atas dilakukan dengan memparafrasa kalimat pendek dalam BSu menjadi satu kalimat yang lebih panjang dalam BSa. Dalam proses parafrasa, penerjemah menambahkan ucapan salam khas agama Islam, Assalamualaikum, yang sudah akrab di telinga para penikmat bekayat. Berikutnya, kalimat "berpalinglah malaikat itu" diparafrasa menjadi kalimat pamit siq bilin sidâ tiang siq rapet ajal: "pamit meninggalkan kita yang ajalnya sudah dekat”. Dalam proses itu ada penambahan dan pengurangan kosakata dalam BSa.

(6) BSu: Terlalu telaga itu luasnya ke bawah dan sempitnya ke atas

BSa: Jari lamun te éngat niki si leq atas bau tekudung isiq tembolaq ato siq nare kedekuq 
beleqnâ laguq eleq bawaq jaq nâ semakin nâ luas jangkâ seare lebih maraq telagâ siq beleq bundar kedekuq eleq dalâm

Bahasa Indonesia: Jadi kalau di bagian atas seperti bisa ditutup dengan nampan atau tempayan saking kecilnya, namun semakin ke bawah telaga itu semakin luas, luasanya sampai satu are lebih, di dalam seperti telaga yang luas dan bundar.

Dalam menerjemahkan teks di atas, penerjemah menggunakan teknik parafrasa. Kalimat "terlalu telaga itu luasnya ke bawah", diparafrasa menjadi kalimat yang lebih panjang dan mengandung penjelasan yang lebih detail; eleq bawaq jaq nâ semakin ne luas jangkâ seare lebih maraq telagâ siq beleq bundar kedekuq eleq dalâm: "semakin ke bawah telaga itu semakin luas, sampai satu are lebih, di dalam seperti telaga yang luas dan bundar." Selanjutnya penerjemah memparafrasa frasa 'sempitnya ke atas' menjadi kalimat si leq atas bau tekudung isiq tembolaq ato siq nare kedekuq beleqnâ:" telaga bagian atas bisa ditutupi oleh tembolaq atau tempayan."

Ada dua jenis parafrasa dalam penerjemahan di atas. Kalimat diparafrasa menjadi kalimat dan frasa menjadi kalimat. Dalam proses parafrasa, penerjemah menggunakan majas metafora untuk menggambarkan sumur tempat dibuangnya Nabi Yusuf.

(7) BSu: Maka dihisabkan lidahnya dan masuklah atasnya empat orang malaikat.

BSa: Penyerioq temateq pemirsâ, pendengah tetemateq, biwihte maraq basâ kasar saq gen muni temateq juluq, ye boq ne tame malaikat beceritâ eleq sidâ tiang si gen mate.

Bahasa Indonesia: Penglihatan
dimatikan pemirsa,
pendengaran dimatikan, bahasa
kasarnya mulut kita yang akan
berbicara dimatikan juga,
kemudian masuk malaikat
bercerita kepada kita yang akan
meninggal dunia.

Teknik parafrasa digunakan dalam penerjemahan di atas dengan cara penambahan kosakata dalam BSa yang memiliki kesetaraan fungsi, sama-sama sebagai alat indera. Kata lidah dalam BSu diberi penambahan kosakata penyerioq (mata) dan pendengah (telinga). Dalam anak kalimat berikutnya ada penambahan kata beceritâ (bercerita) dalam BSa. Pola penerjemahan di atas adalah parafrasa kalimat majemuk setara menjadi kalimat setara dengan penambahan kosakata dalam BSa yang mendukung pemahaman makna.

\subsection{Teknik Penjelasan Tambahan (Contextual Conditioning)}

Teknik penjelasan tambahan (contextual conditioning) adalah menerjemahkan dengan memberikan padanan dan kata tambahan dalam teks sasaran (TSa) (Newmark dan Hatim, lihat Modul Diklat Fungsional Penerjemah, 2013:34). Tujuan pemberian padanan dan kata tambahan tersebut adalah untuk menjelaskan sesuatu yang tidak dipahami pada teks sumber (TSu). Berikut ini adalah proses penerjemahan menggunakan teknik penjelasan tambahan.

(8) BSu: Inilah pasal pada menyatakan keluar nyawa daripada badan.

BSa: Bu maraq atur tiang leq muqaddimah saq baruq, Pasal niki pasal sugul nyawen sidâ tiang lengan jasad saq kasat atao lazim biase tesebut mate, iye si gen tesampeang. 
Bahasa Indonesia: Seperti yang saya sampaikan dalam bagian pembukaan tadi, pasal ini adalah pasal keluar nyawa kita dari jasad kasar atau biasa disebut mati, itu yang akan disampaikan.

Dalam proses penerjemahan di atas, penerjemah menggunakan teknik penjelasan tambahan. Ungkapan sugul nyawân sidâ tiang lengan jasad saq kasat, "keluarnya nyawa dari badan" diberi penjelasan tambahan atao lazim biasâ tesebut mate, iye si gen tesampeang "atau biasa disebut mati, inilah yang akan disampaikan". Penjelasan tambahan ini adalah ungkapan penerjemah sendiri dengan maksud agar penikmat bekayat mudah memahami pesan yang disampaikan. Oleh karena itu, penerjemah menggunakan kata-kata yang sudah lazim atau akrab di tengah-tengah masyarakat, yakni kata "mati" untuk menjelaskan makna "keluar nyawa daripada badan".

(9) BSu: Sesaat kemudian masuklah lagi malaikat ketiga.

BSa: Bo aten tebejawab jama'ah, semaiq te mate, rezekin te wah tutuq, makanante niki, minuman te wah tutuq. Nah jari wah demen wah sugul malaikat si keduâ, niki muq tame malik malaikat si ketelu.

Bahasa Indonesia: Terus hati kita menjawab jama'ah, pantas kita mati, rezeki kita telah habis, makanan dan minuman kita telah habis. Nah setelah malaikat yang kedua keluar masuklah lagi malaikat ketiga.

Kalimat “... tame malik malaikat si ketelu: "masuklah lagi malaikat ketiga" diberi penjelasan tambahan di depannya nah jari wah demen wah sugul malaikat si keduâ: "nah setelah malaikat yang kedua keluar. "Penjelasan tambahan itu adalah kata-kata penerjemah sendiri dengan maksud agar penikmat bekayat mudah memahami dan menghayati jalannya kisah yang disampaikan. Penjelasan tambahan itu mengandung logika kronologis cerita, masuknya malaikat ketiga didahului dengan keluarnya malaikat kedua. Penjelasan tambahan itu juga berfungsi sebagai penghubung dengan kalimat sebelumnya untuk memunculkan kepaduan teks - lisan.

(10) BSu: Maka berkatalah ia, he hamba Allah akulah malaikat yang diwakilkan dengan ajal engkau.

BSa: Taoq dâ tiang niki Bapaq, taoq dâ tiang niki Ibu, tiang si gisiang sidâ jatah umur, jatah umurdâ idup leq dunia siq piaq de modal, si kadun dâ berusahâ umur de sino, nah tiang wah niki, temaaf laguq bapak tiang ceritaq sidâ.

Bahasa Indonesia: Tahukah Bapak siapa saya ini? Tahukan Ibu siapa saya ini? Saya yang mengatur jatah umur kamu, jatah umur hidup di dunia yang kamu jadikan modal, umur yang kamu gunakan untuk berusaha. Nah saya lah ini, tapi maaf Bapak saya ceritakan ini...

Dalam proses penerjemahan di atas, penerjemah menerapkan teknik penjelasan tambahan. Kata "ajal" diterjemahkan ke BSa menjadi 'jatah umurdâ idup leq dunia: jatah umurmu hidup di dunia'. Selanjutnya, penerjemah menyampaikan penjelasan tambahan untuk kata 'ajal' yakni "siq piaq de modal, si kadun dâ berusahâ umur de sino: yang menjadi modal kamu, umur yang kamu gunakan untuk berusaha." Penjelasan tambahan ini diperlukan dalam proses penerjemahan ini karena seandainya kata "ajal: jatah umur" tidak diberi penjelasan 
tambahan belum tentu dapat dipahami oleh semua kalangan masyarakat penikmatnya.

(11) BSu: Maka pada ketika demikian itulah sukalah ia dan manis mukanya.

BSa: Eleq tatkalân teboyaq kasete saq seneng saq solah, seneng kemos kedekuq kikit kakak tecemoh laloq sengaq tivi niki ruân kasetnâ sandiwarânâ, kelempanâ solah jari seneng keq sidâ tiang leq parak temate niki tesetelang kasete saq solah.

Bahasa Indonesia: Ketika dia tonton kasetnya yang senang dan bagus, dia tersenyum bahagia, tertawa lebar, tertawa lebar karena kaset rekaman sandiwara amal yang ditampilkan di layar tv sangat bagus, jalan ceritanya bagus sehingga kita bahagia saat meninggalkan dunia.

Dalam menerjemahkan teks di atas, penerjemah memberikan penjelasan tambahan yang panjang untuk menerjemahkan frasa 'sukalah ia dan manis mukanya'. Frase itu diterjemahkan menjadi 'kemos kedekuq kikitkakaktecemoh laloq'. Selanjutnya penerjemah memberikan penjelasan tambahan 'sengaq tivi niki ruân kasetnâ sandiwaranâ, kelempanâ solah jari seneng keq sidâ tiang leq parak temate niki tesetelang kasetâ saq solah: karena kaset rekaman sandiwara amal yang ditampilkan di layar tv sangat bagus, jalan ceritanya bagus sehingga kita bahagia saat meninggalkan dunia'. Penjelasan tambahan itu berisi hubungan 'sebab-akibat', penjelasan tambahan itu berisi 'sebab' dan yang dijelaskan adalah 'akibat'. Selain itu, penerjemah juga menambahkan frase 'kikit kakak' sebagai penjelasan tambahan dari frasa seneng kemos: "tersenyum bahagia". Frasa kikit kakak berarti tertawa lebar, yang menunjukkan betapa senang dan bahagianya orang yang meninggal dunia ketika diperlihatkan amal-amal kebaikannya yang bagus dan banyak. Dengan penjelasan tambahan itu, pembacaan bekayat menjadi tidak kaku dan seolah-olah bukan hasil terjemahan.

(12) BSu: Maka tatkala itu air mata Yahuda pun mengalir sampai ke jenggotnya.

BSa: Araq semeton nâ siq paling beleq satu-satunâ keq periak asek jangkâ nâ ngélék ke aiq penyerminâ jangkâ nâ basaq baok semetnâ keq Yahuda.

Bahasa Indonesia: Ada seorang saudara tertua Yusuf satu-satunya kasihan kepadanya sampai mengalir air matanya membahasahi jenggotnya yaitu Yahuda.

Tokoh Yahuda diberi penjelasan tambahan dalam BSa Araq semeton ne siq paling beleq satu-satunâ keq periak "Ada seorang saudara tertua Yusuf satu-satunya kasihan kepadanya". Kemudian tokoh Yahuda ini disebutkan pada akhir kalimat. Pemberian penjelasan tambahan ini berguna untuk mempermudah mengenal tokoh Yahuda, salah satunya dengan menyebut hubungan kerabatnya dengan Yusuf.

\subsection{Teknik Kompensasi}

Salah satu teknik yang diterapkan dalam penelitian penerjemahan teks bekayat di Desa Taman Ayu, Kecamatan Gerung adalah teknik kompensasi. Teknik kompensasi maksudnya adalah penggantian kata atau kosakata bahasa sumber kemudian menggantinya dengan kosakata lain dalam BSa. Berikut adalah teks bekayat yang diterjemahkan menggunakan teknik kompensasi.

(13) BSu: Maka berkatalah ia, he hamba Allah, akulah malaikat yang diwakilkan dengan ajal engkau. 
Teknik Terjemahan Lisan... (Safoan Abdul Hamid)| 161

BSa: $\quad$ Taoq dâ tiang niki Bapaq, taoq de tiang niki Ibu, tiang si gisiang sidâ jatah umur, jatah umurdâ idup leq dunia siq piaq de modal, si kadun dâ berusahâ umur de sino, nah tiang wah niki, temaaf laguq bapak tiang ceritaq sidâ.

Bahasa Indonesia: Tahukah Bapak siapa saya? Saya yang mengurus jatah umur, jatah umur engkau hidup di dunia yang engkau jadikan modal, umur yang engkau gunakan berusaha, nah saya lah ini. Maaf ya saya ceritakan ini kepada engkau.

Terdapat dua unsur penggunaan teknik kompensasi dalam terjemahan di atas. Pertama, frasa "hamba Allah" dihilangkan dan dikompensasi menjadi "Bapak" dan "ibu". Kata "Bapak" adalah kata sapaan yang lazim digunakan dalam bahasa Sasak untuk menyapa orang yang dihormati dengan logika penerjemah seolah-olah berbicara langsung atau menyapa penikmat bekayat. Selain itu, pemunculan kata "ibu" dalam BSa akan memenuhi keterwakilan gender karena frasa "hamba Alah" dapat mewakili laki-laki dan perempuan. Kedua, frasa "akulah malaikat" dihilangkan dan dikompensi dengan frasa tiang niki "akulah atau aku ini." Kedua kata dalam frasa tiang niki termasuk kosakata halus bahasa Sasak, dengan alasan kesantunan penyampaian pesan. Penggunaan teknik kompensasi dalam penerjemahan di atas dilakukan dengan penggantian frasa menjadi kata dan frasa menjadi frasa.

(14) BSu: Maka pada ketika demikian itulah mengalir peluhnya ia.

BSa: Dekuqnâ maraq tependiq isiq ujan keq daur usengtâ tatkalâ tesetelang pegaweante siq salaq, laguq bagi sidâ tiang siq lueq salaq, lamun dengan ndeq naraq salaq ne jaq kosong kasetnâ si leq kiri niki.

Bahasa Indonesia: Seperti bermandikan hujan peluh kita ketika diputar rekaman pekerjaan kita yang salah. Namun itu bagi kita yang banyak kesalahan. Tapi bagi yang tidak ada kesalahan kaset rekaman yang di sebelah kiri kosong.

Pola penggunaan teknik kompensasi pada penerjemahan di atas adalah dengan penghilangan kata "mengalir" dan dikompensasi menjadi frasa maraq tependiq isiq ujan: "seperti bermandikan air hujan" dalam BSa. Frasa pengganti dalam BSa adalah majas metafora. Penggunaan majas adalah untuk tujuan estetika.

(15) BSu: Lihatlah olehmu akan anak Rahil ini takutlah ia akan mati.

BSa: No deserioq kakaq ruenâ kanak temanja isiq mamiq nâ sekedar tesebut aran mate takutnâ siq tutuq balong sini kakaq.

Bahasa Indonesia: Itu lihat kakak anak yang dimanja orang tuanya, hanya disebutkan "mati" dia begitu takut kakak.

Terdapat dua unsur penggunaan teknik kompensasi dalam penerjemahan di atas. Frasa anak Rahil dalam BSu dihilangkan dan dikompensasi menjadi kanak temanja isiq mamiq nâ "anak yang dimanja orang tuanya" dalam BSa. Pola penerapan teknik kompensasi ialah kompensasi frasa dengan frasa yang lebih panjang.

(16) BSu: Dan adalah telaga itu diperbuat oleh anak Nuh as.

BSa: Laeq ribuan taun wah tepinaq lingkoq sino isiq nuh as.

Bahasa Indonesia: Dahulu ribuan tahun lamanya dibuat sumur itu oleh Nuh as.

Dalam penerjemahan teks bekayat di atas, teknik kompensasi digunakan pada 
tataran kata. Kata"telaga" dihilangkan dan dikompensasi dengan lingkoq dalam BSa. Dalam kisah Qishashul Anbiya tersebut, Nabi Yusuf dibuang ke dalam sumur, bukan ke dalam telaga seperti yang ada dalam BSu. Oleh karena itu, dalam BSa (bahasa Sasak) digunakan kata lingkoq. Adapun kata "telaga" dalam bahasa Melayu (BSu) dapat bermakna sumur.

\section{Penutup}

Bekayat adalah salah satu jenis tradisi lisan pembacaan hikayat yang berkembang pada masyarakat suku Sasak di Pulau Lombok. Hikayat yang dibaca menggunakan bahasa Melayu aksara Arab. Tradisi ini memiliki fungsi strategis yakni transmisi nilai-nilai ajaran Agama Islam. Agar penikmat bekayat dapat memahami pesan yang disampaikan, dalam proses pembacaan bekayat ada tahapan penerjemahan lisan teks hikayat yang dibaca dari bahasa Melayu (BSu) ke bahasa Sasak (BSa).

Dalam proses penerjemahan, penerjemah atau pelogat menggunakan berbagai teknik yang disesuaikan dengan kebutuhan penikmat. Berdasarkan analisis data menggunakan metode komparatif intralingual dan metode deskriptif ditemukan bahwa aktifitas bekayat di Desa Taman Ayu, Kecamatan Gerung, penerjemah menggunakan beberapa teknik yaitu teknik parafrasa, teknik penjelasan tambahan (contextual conditioning), dan teknik kompensasi. Teknik ini diterapkan oleh penerjemah bukan berdasarkan pengetahuannya tentang teori menerjemahkan tapi semata-mata karena pengalaman danusaha adaptasi dengan kebutuhan penikmat.

\section{Daftar Pustaka}

Baried, Siti Barorah dkk. (1994). Pengantar Teori Filologi. Yogyakarta: BPPF Fakultas Sastra Gadjah Mada.

Djamaris, Edwar. (1993). Menggali Khazanah Sastra Melayu Klasik. Jakarta: Balai Pustaka.

Hikayat (2014).

http://melayuonline.com/ind/cultur e/dig/625/hikayat. diakses tanggal 16 Oktober 2014.

Hoed, Benny Hoedoro. (2006). Penerjemahan dan Kebudayaan. Jakarta: Pustaka Jaya.

Moeliono, Anton M. dkk. (2013). Kamus Besar Bahasa Indonesia. Jakarta: PT. Gramedia Pustaka Utama.

Nababan, M. Rudolf. (2008). Teori Menerjemah Bahasa Inggris. Yogyakarta: Pustaka Pelajar.

Newmark, Peter. (1988). Textbook of Translation. London: Prentice Hall.

Saharudin. (2013). Bekayat: Sastra Lisan Islamisasi Sasak dalam Bayang Kepunahan. Conference Proceedings AICIC 12. (pp. 14161428). Surabaya, Indonesia.

Suryawinata, Zuchridin, dkk. (2003). Translation: Bahasa Teori dan Penuntun Praktis Menerjemahkan. Yogyakarta: Kanisius. 
Teknik Terjemahan Lisan... (Safoan Abdul Hamid)| 163

Tim Penyusun. (2013). Pengenalan

Tim Penyusun. (2013). Strategi Penerjemahan Tulis. Dalam Tim Penyusun, Modul Pendidikan dan Pelatihan Fungsional Penerjemahan. Dalam Tim Penyusun, Modul Pendidikan dan Pelatihan Fungsional Penjenjangan Penerjemah Tingkat Penjenjangan Penerjemah Tingkat Pertama Angkatan IV. Jakarta: Pertama Angkatan IV. Jakarta: Kementerian Sekretariat Negara. Kementerian Sekretariat Negara. 